\title{
A COVID-19 antibody curbs SARS-CoV-2 nucleocapsid protein-induced complement hyperactivation
}

\section{Sisi Kang}

Sun Yat-sen University

\section{Mei Yang}

The Fifth Affiliated Hospital of Sun Yat-sen University

\section{Suhua He}

The Fifth Affiliated Hospital of Sun Yat-sen University

\section{Yueming Wang}

Jinan University; Zhuhai Trinomab Biotechnology Co., Ltd.

\section{Xiaoxue Chen}

Department of Experimental Medicine, Guangdong Provincial Key Laboratory of Biomedical Imaging, The Fifth affiliated Hospital, Sun Yat-sen University, Zhuhai, 519000

\section{Yao-Qing chen}

Sun Yat-sen University

\section{Zhongsi Hong}

Fifth Affiliated Hospital of Sun Yat-sen University

Jing Liu

The Fifth Affiliated Hospital of Sun Yat-sen University

\section{Guanmin Jiang}

Fifth Affiliated Hospital of Sun Yat-sen University

\section{Qiuyue Chen}

Sun Yat-sen University

\section{Ziliang Zhou}

Sun Yat-sen University https://orcid.org/0000-0002-6801-4180

\section{Zhechong Zhou}

Sun Yat-sen University

\section{Zhaoxia Huang}

Sun Yat-sen University

\section{Xi Huang}

Fifth Affiliated Hospital of Sun Yat-sen University

\section{Huanhuan He}

Guangdong Provincial Engineering Research Center of Molecular Imaging 


\section{Weihong Zheng}

Jinan University; Zhuhai Trinomab Biotechnology Co., Ltd.

Hua-Xin Liao

Jinan University; Zhuhai Trinomab Biotechnology Co., Ltd.

\section{Fei Xiao}

Sun Yat-sen University

\section{Hong Shan}

Sun Yat-sen University

Shoudeng Chen ( $\nabla$ chenshd5@mail.sysu.edu.cn)

Sun Yat-sen University https://orcid.org/0000-0002-7634-2141

\section{Article}

Keywords: human monoclonal antibody, COVID-19, SARS-CoV-2, nucleocapsid protein, crystal structure, complement hyperactivation, viral protein targeting therapy, MASP-2

Posted Date: December 2nd, 2020

DOl: https://doi.org/10.21203/rs.3.rs-106760/v1

License: (c) (1) This work is licensed under a Creative Commons Attribution 4.0 International License. Read Full License

Version of Record: A version of this preprint was published at Nature Communications on May 11th, 2021. See the published version at https://doi.org/10.1038/s41467-021-23036-9. 
1 A SARS-CoV-2 antibody curbs viral $\mathbf{N}$ protein-induced

2 complement hyperactivation

3 Sisi Kang ${ }^{1 *}$, Mei Yang $^{1^{*}}$, Suhua $\mathrm{He}^{1 *}$, Yueming Wang ${ }^{2,3^{*}}$, Xiaoxue Chen ${ }^{1}$, Yao-

4 Qing Chen ${ }^{4}$, Zhongsi Hong ${ }^{5}$, Jing Liu ${ }^{6}$, Guanmin Jiang ${ }^{7}$, Quyue Chen ${ }^{1}$, Ziliang

5 Zhou ${ }^{1}$, Zhechong Zhou ${ }^{1}$, Zhaoxia Huang ${ }^{1}$, Xi Huang ${ }^{8}$, Huanhuan $\mathrm{He}^{1}$, Weihong

6 Zheng ${ }^{2,3}$, Hua-Xin Liao ${ }^{2,3, \#, ~ F e i ~ X i a o ~}{ }^{1,5, \#}$, Hong Shan ${ }^{1,9, \#, ~ S h o u d e n g ~ C h e n ~}{ }^{1,10, \#}$

7 1. Molecular Imaging Center, Guangdong Provincial Key Laboratory of

8 Biomedical Imaging, The Fifth Affiliated Hospital, Sun Yat-sen University,

9 Zhuhai, 519000, China

10 2. Institute of Biomedicine, Jinan University, Guangzhou, 510632, China

11 3. Zhuhai Trinomab Biotechnology Co., Ltd., Zhuhai, 519040, China

12 4. School of Public Health (Shenzhen), Sun Yat-sen University, Shenzhen,

13 China

14 5. Department of Infectious Disease, The Fifth Affiliated Hospital, Sun Yat-sen

15 University, Zhuhai, 519000, China

16 6. Department of Respiratory Disease, The Fifth Affiliated Hospital, Sun Yat-sen

17 University, Zhuhai, 519000, China

18 7. Department of Clinical laboratory, The Fifth Affiliated Hospital of Sun Yat-sen

19 University, Zhuhai, 519000, China

20 8. Center for Infection and Immunity, The Fifth Affiliated Hospital, Sun Yat-sen

21 University, Zhuhai, 519000, China 
22 9. Department of Intervention Medicine, The Fifth Affiliated Hospital, Sun Yat23 sen University, Zhuhai, 519000, China

24 10. Department of Experimental Medicine, The Fifth Affiliated Hospital, Sun Yat25 sen University, Zhuhai, 519000, China

26 * These authors contributed equally to this work

27 \# Co-correspondence: Shoudeng Chen (chenshd5@mail.sysu.edu.cn); Hong 28 Shan (shanhong@mail.sysu.edu.cn ); Fei Xiao (xiaof35@mail.sysu.edu.cn ); 29 Hua-Xin Liao (tliao805@jnu.edu.cn ) 


\section{Summary}

31 Although human antibodies elicited by the severe acute respiratory

32 syndrome coronavirus 2 (SARS-CoV-2) nucleocapsid (N) protein are

33 profoundly boosted upon infection, little is known about the function of $\mathrm{N}$ -

34 reactive antibodies. Herein, we isolated and profiled a panel of $32 \mathrm{~N}$

35 protein-specific monoclonal antibodies (mAbs) from a quick recovery

36 coronavirus disease-19 (COVID-19) convalescent patient who had dominant

37 antibody responses to the SARS-CoV-2 N protein rather than to the SARS-

38 CoV-2 spike (S) protein. The complex structure of the $\mathbf{N}$ protein RNA

39 binding domain with the mAb with the highest binding affinity (nCoV396)

40 revealed changes in the epitopes and antigen's allosteric regulation.

41 Functionally, a virus-free complement hyperactivation analysis

42 demonstrated that $\mathrm{nCoV} 396$ specifically compromises the $\mathbf{N}$ protein-

43 induced complement hyperactivation, which is a risk factor for the

44 morbidity and mortality of COVID-19 patients, thus laying the foundation

45 for the identification of functional anti-N protein mAbs.

46 Keywords: human monoclonal antibody, COVID-19, SARS-CoV-2, nucleocapsid

47 protein, crystal structure, complement hyperactivation, viral protein targeting

48 therapy, MASP-2 


\section{Main}

50 The fatality rate of critical condition coronavirus disease 2019 (COVID-19)

51 patients is exceptionally high $(40 \%-49 \%)^{1,2}$. Acute respiratory failure and

52 generalized coagulopathy are significant aspects associated with morbidity and

53 mortality ${ }^{3-5}$. A subset of severe COVID-19 patients has distinct clinical features

54 compared to classic acute respiratory distress syndrome (ARDS), with delayed

55 onset of respiratory distress ${ }^{6}$ and relatively well-preserved lung mechanics

56 despite the severity of hypoxemia ${ }^{7}$. It has been reported that complement-

57 mediated thrombotic microvascular injury in the lung may contribute to atypical

58 ARDS features of COVID-19, accompanied by extensive deposition of the

59 alternative pathway (AP) and lectin pathway (LP) complement components ${ }^{8}$.

60 Indeed, complement activation is found in multiple organs of severe COVID-19

61 patients in several other studies ${ }^{9,10}$, as well as in patients with severe acute

62 respiratory syndrome (SARS) ${ }^{11,12}$. A recent retrospective observational study of

6311,116 patients revealed that complement disorder was associated with the 64 morbidity and mortality of COVID-19 13 .

65 The nucleocapsid $(\mathrm{N})$ protein of severe acute respiratory syndrome coronavirus 66 2(SARS-CoV-2), the etiology agent of COVID-19, is one of the most abundant

67 viral structural proteins with multiple functions inside the viral particles, the host 68 cellular environment, and in ex vivo experiments ${ }^{14-20}$. Among these functions, a

69 recent preprint study found that the SARS-CoV-2 N protein bound to MBL

70 (mannan-binding lectin)-asssociated serine protease 2 (MASP-2) and resulted in 
71 complement hyperactivation and aggravated inflammatory lung injury ${ }^{19}$.

72 Consistently, the highly pathogenic SARS-CoV N protein was also found to bind 73 with MAP19, an alternative product of MASP-2 ${ }^{21}$.

74 Although systemic activation of complement plays a pivotal role in protective 75 immunity against pathogens, hyperactivation of complement may lead to 76 collateral tissue injury. Thus, how to precisely regulate virus-induced 77 dysfunctional complement activation in COVID-19 patients remains to be 78 elucidated. The SARS-CoV-2 $\mathrm{N}$ protein is a highly immunopathogenic viral 79 protein that elicits high titers of binding antibodies in humoral immune 80 responses ${ }^{22-24}$. Several studies have reported the isolation of human monoclonal 81 antibodies (mAbs) targeting the SARS-CoV-2 spike (S) protein, helping explain

82 the possible developing therapeutic interventions for COVID-1922,25-29. However,

83 little is known about the potential therapeutic applications of $\mathrm{N}$ protein-targeting 84 mAbs in the convalescent B cell repertoire. Herein, we report a human mAb 85 derived from the COVID-19 convalescent patient that specifically targets the 86 SARS-CoV-2 $\mathrm{N}$ protein and functionally compromises complement 87 hyperactivation ex vivo.

\section{Isolation of $\mathbf{N}$ protein-reactive $\mathbf{m A b s}$}

89 To profile the antibody response to the SARS-CoV-2 N protein in patients during

90 the early recovery phase, we collected blood samples from six convalescent 91 patients seven to 25 days after the onset of the disease symptoms. All patients 92 recovered from COVID-19 during the outbreak in Zhuhai, Guangdong Province, 
93 China, with ages ranging from 23 to 66 years (Extended Data Table 1). Our 94 work and use of patients' samples is in accordance with the declaration of

95 Helsinki, medical ethics standards and China's laws. Our study was approved by 96 the Ethics Committee of The Fifth Affiliated Hospital, Sun Yat-sen University, and 97 all patients signed informed consent forms. SARS-CoV-2 nasal swabs reverse 98 transcription polymerase chain reaction (RT-PCR) tests were used to confirm 99 that all 6 COVID-19 patients were negative for SARS-CoV-2 at the time of blood 100 collection. Plasma samples and peripheral blood mononuclear cells (PBMCs) 101 were isolated for serological analysis and antibody isolation. Serum antibody 102 titers to SARS-CoV-2 $\mathrm{S}$ and $\mathrm{N}$ proteins were measured by enzyme-linked 103 immunosorbent assay (ELISA) (Figure 1a, 1b, and Extended Data Table 1). 104 Serologic analysis demonstrated that serum antibody titers to the $\mathrm{N}$ protein were 105 substantially higher than those to the $S$ protein in most of the patients. For 106 example, ZD004 and ZD006 had only minimal levels of antibody response to the $107 \mathrm{~S}$ protein, while they had much higher antibody titers to the $\mathrm{N}$ protein. Notably, 108 the time from disease onset to complete recovery from clinical symptoms of 109 COVID-19 patient ZD006 was only 9 days (Extended Data Table 1).

110 To take advantage of patient ZD006, who was still in the early recovery phase 111 with a high possibility of a high percentage of antigen-specific plasma cells, 112 single plasma cells (Figure 1c) with the phenotype of CD3/CD14//CD16$113 / \mathrm{CD} 235 \mathrm{a} / \mathrm{CD} 19^{+} / \mathrm{CD} 20^{\mathrm{low}-\mathrm{neg}} / \mathrm{CD} 27^{\mathrm{hi}} / \mathrm{CD} 38^{\mathrm{hi}}$ as well as antigen-specific memory $\mathrm{B}$ 114 cells with the phenotype of $\mathrm{CD} 19^{+} / \mathrm{CD} 27^{+}$(Figure 1d) were sorted from PBMCs 115 of patient ZD006 by fluorescence-activated cell sorting (FACS). To ensure an 
116 unbiased assessment, the sorting of antigen-specific memory B cells was carried

117 out with combined probes for both fluorophore-labeled $\mathrm{S}$ and $\mathrm{N}$ recombinant

118 proteins. Variable regions of immunoglobulin (Ig) heavy and light chain gene

119 segment $\left(\mathrm{V}_{\mathrm{H}}\right.$ and $\mathrm{V}_{\mathrm{L}}$, respectively) pairs from the sorted single cells were

120 amplified by RT-PCR, sequenced, annotated and expressed as recombinant

121 mAbs using the methods described previously ${ }^{30}$. Recombinant mAbs were 122 screened against SARS-CoV-2 S and N proteins. In total, we identified $32 \mathrm{mAbs}$

123 that reacted with the SARS-CoV-2 N protein, including $20 \mathrm{mAbs}$ from plasma 124 cells and 12 mAbs from memory B cells (Extended Data Table 2). We found that $125 \lg 1$ is the predominant isotype at $46.9 \%$, followed by $\lg G 3(25.0 \%)$, IgA ( $18.8 \%)$, $126 \operatorname{lgG} 2(6.3 \%)$ and IgM (3.1) (Figure 1e). $V_{H}$ gene family usage in SARS-CoV-2 N 127 protein-reactive antibodies was $18.8 \%$ for $V_{H} 1,62.5 \%$ for $V_{H} 3,9.4 \%$ for $V_{H} 4$, $1286.2 \%$ for $\mathrm{V}_{\mathrm{H}} 5$ and $3.1 \%$ for $\mathrm{V}_{\mathrm{H}} 7$, respectively (Figure 1f), which was similar to the 129 distribution of $\mathrm{V}_{\mathrm{H}}$ families collected in the NCBI database. Nine of 32 SARS-CoV-

$1302 \mathrm{~N}$ protein-reactive antibodies had no mutations from their germline $\mathrm{V}_{\mathrm{H}}$ and $\mathrm{V}_{\mathrm{H}}$ 131 gene segments (Figure 1f, Extended Data Table 2). The average mutation 132 frequency of the remaining mutated antibodies was $5.3 \%(+/-3.6 \%)$ in $\mathrm{V}_{\mathrm{H}}$ and $133 \quad 3.5 \%(+/-2.7 \%)$ in $V_{L}$.

134 Consistent with the lower serum antibody titers to the SARS-CoV-2 S protein, we 135 identified only eight SARS-CoV-2 S protein-reactive mAbs, including 5 antibodies 136 from plasma cells and three antibodies from memory $B$ cells. The $V_{H}$ gene 137 segment of the $S$ protein-reactive antibodies had either no (6/8) or minimal 138 (1/300) mutations (Figure 19). There were no significant differences in 
139 complementarity-determining region 3 (CDR3) length in amino acid residues

140 between the N- (Figure 1h) and S-reactive antibodies (Figure 1i).

141 Approximately a quarter of antibodies directed to the $\mathrm{N}$ protein (Figure 1f) and 142 almost all of antibodies to the $S$ protein that had no or minimal mutations from 143 their germlines (Figure 19) had a primary antibody response similar to other 144 typical primary viral infections. However, relatively high $V_{H}$ mutation frequencies 145 (mean of 5.7\%) of the majority of antibodies to the $\mathrm{N}$ proteins were more similar 146 to the mutation frequencies of antibodies from the secondary responses to the 147 influenza vaccination reported previously ${ }^{31}$. Although patient ZD006 was 148 hospitalized for only nine days after the onset of COVID-19 symptoms, the 149 patient had high serum antibody titers, and the majority of the isolated $\mathrm{N}$-reactive 150 antibodies had a high mutation frequency, whereas the S-reactive antibodies had 151 no or minimal mutations. These results reflect a much stronger antigen 152 stimulation to the host driven by the SARS-CoV-2 N protein than by the S protein.

\section{Binding characterizations of anti-N mAbs}

154 To determine the antigenic targets by the N-reactive antibodies, we next 155 analyzed the binding activities by ELISA with variant constructs of the $\mathrm{N}$ protein 156 (full length $\mathrm{N}$ protein (N-FL): 1-400; $\mathrm{N}$ protein $\mathrm{N}$-terminal domain (N-NTD): $41-$ 157 174; and $\mathrm{N}$ protein C-terminal domain (N-CTD): 250-364) (Figure 2a). Among 158 the 32 mAbs that bound to N-FL, 13 antibodies bound to N-NTD, and one 159 antibody bound to N-CTD (Figure 2 b). A total of nine antibodies, including one 160 antibody (nCoV400) that bound to N-CTD, seven mAbs (nCoV396, nCoV416, 
$161 \mathrm{nCoV424,} \mathrm{nCoV425,} \mathrm{nCoV433,} \mathrm{nCoV454,} \mathrm{and} \mathrm{nCoV457)} \mathrm{that} \mathrm{bound} \mathrm{to} \mathrm{N-NTD}$ 162 and one mAb (nCoV402) that bound only to N-FL but not to the other variant $\mathrm{N}$ 163 proteins, were chosen as representative antibodies for further studies. Purified 164 antibodies were confirmed to bind the N-FL protein by ELISA (Figure 2c). The 165 affinity of these antibodies to the N-FL protein was measured by surface plasmon 166 resonance (SPR) (Figure 2d). In an effort to further characterize the functional 167 and structural relationships, three antibodies, nCoV396, nCOV416 and nCOV457, 168 were selected for the production of recombinant fragment antigen-binding (Fab) 169 antibodies based on their unique characteristics. The mAb nCoV396 has a $V_{H}$

170 mutation frequency of $2.8 \%$ but a high binding affinity with a $K_{D}$ of $1.02 \mathrm{nM}$ 171 (Figure 2d) to the $\mathrm{N}$ protein. The mAbs nCOV416 and nCOV457 have high $\mathrm{V}_{\mathrm{H}}$ 172 mutations at $11.1 \%$ and $8.7 \%$, respectively and have a binding affinity to the $\mathrm{N}$ 173 protein with $K_{D}$ values of $7.26 \mathrm{nM}$ and $12.6 \mathrm{nM}$, respectively (Figure $2 \mathrm{~d}$, 174 Extended Data Table 3).

\section{Complex structure of mAb with N-NTD}

176 To investigate the molecular interaction mechanism of the mAb nCoV396 with 177 the N protein, we next solved the complex structure of the SARS-CoV-2 N-NTD 178 with the $\mathrm{nCoV} 396$ Fab $\mathrm{nCoV} 396 \mathrm{Fab}$ at a $2.1 \AA$ resolution by X-ray 179 crystallography. The final structure was fitted with the visible electron density 180 spanning residues 49-173 (SARS-CoV-2 N-NTD), 1-220 (nCoV396Fab, the 181 heavy chain of the Fab), and 1-213 (nCoV396Fab, the light chain of Fab, except 182 for the residues ranging from 136-141). The complete statistics for the data 183 collection, phasing, and refinement are presented in Extended Data Table 4. 
184 With the help of the high-resolution structure, we were able to designate all 185 complementarity-determining regions (CDRs) in nCoV396Fab as the following: 186 light chain CDR1, residues 23-32 (L-CDR1), light chain CDR2, residues 51-54 (L187 CDR2), light chain CDR3, residues 94-100 (L-CDR3), heavy chain CDR1, 188 residues 26-33 (H-CDR1), heavy chain CDR2, residues 51-57 (H-CDR2), and 189 heavy chain CDR3, residues 99-108 (H-CDR3). Among them, we identified the 190 interaction interface between N-NTD and L-CDR1, L-CDR3, H-CDR1, H-CDR2, 191 and $\mathrm{H}-\mathrm{CDR} 3$ of $\mathrm{nCoV} 396 \mathrm{Fab}$ with an unambiguous electron density map (Figure 192 3a, Extended Data Figure 1a).

193 The interacting CDRs pinch the CT tail of the SARS-CoV-2 N-NTD (residues 194 ranging from 159 to 172), with extensive binding contacts and a buried surface 195 area of 1,079 $\AA^{2}$ (Extended Data Table 5). Light chain L-CDR1 and L-CDR3 of 196 nCoV396Fab interact with residues ranging from 159-163 of N-NTD via 197 numerous hydrophilic and hydrophobic contacts (Figure 3b, Extended Data 198 Figure 1b). Notably, the SARS-CoV-2 N-NTD residue Q163 is recognized by the 199 L-CDR3 residue T95 via a hydrogen bond and simultaneously stacks with the L200 CDR3 residue W96 and the L-CDR1 residue Y31 (Figure 3c). In addition, a 201 network of interactions from the heavy chain $\mathrm{H}-\mathrm{CDR} 2$ and $\mathrm{H}-\mathrm{CDR} 3$ of 202 nCoV396Fab to residues 165-172 of N-NTD suggests that the conserved residue 203 K169 of SARS-CoV-2 N-NTD has a critical role in nCoV396 antibody binding. $204 \mathrm{~K} 169$ is recognized via hydrogen bonds with the E99 $\delta$-carboxyl group and the 205 T100, D102, S105 main-chain carbonyl groups inside the H-CDR3 of 206 nCoV396Fab (Figure 3d). In addition, SARS-CoV-2 N-NTD L167 also interacts 
207 with $133, \mathrm{~V} 50, \mathrm{~N} 57$, and A59 of H-CDR1 and H-CDR2 of nCoV396Fab through

208 hydrophobic interactions (Figure 3e). Interestingly, all three residues (Q163,

209 L167, and K169) of SARS-CoV-2 N-NTD are relatively conserved in the highly

210 pathogenic betacoronavirus $\mathrm{N}$ protein (Extended Data Figure 2a), which implies

211 that nCoV396 may cross-interact with the SARS-CoV N protein or the Middle

212 East respiratory syndrome coronavirus (MERS-CoV) N protein. Indeed, the

213 binding affinities measured by SPR analysis demonstrate that nCoV396 interacts

214 with the SARS-CoV N protein and the MERS-CoV N protein with a $K_{D}$ of $7.4 \mathrm{nM}$

215 (Extended Data Figure 2b - c).

216 To discover the conformational changes between the SARS-CoV-2 N-NTD apo-

217 state and the antibody-bound state, we next superimposed the complex structure

218 with the N-NTD structure (PDB ID: 6M3M) ${ }^{14}$. The superimposition results suggest

219 that the CT tail of SARS-CoV-2 N-NTD unfolds from the basic palm region upon

220 nCoV396Fab binding (Figure 3f), which likely contributes to the allosteric

221 regulation of the normal full-length $\mathrm{N}$ protein function. Additionally, nCoV396Fab

222 binding results in a $7.4 \AA$ movement of the $\beta$-finger region outward from the RNA

223 binding pocket, which may enlarge the RNA binding pocket of the $\mathrm{N}$ protein

224 (Figure 3f).

225 In summary, our crystal structural data demonstrated that the human mAb

$226 \mathrm{nCoV} 396$ recognizes the SARS-CoV-2 N protein via a pinching model, resulting

227 in a dramatic conformational change in residues 159 to 172 , which is the linker

228 region of N-NTD that is connected with other domains. 


\section{MAb curbs $\mathbf{N}$-induced complement activation}

230 Although a recent study suggests that the complement cascade is hyperactive by

231 the $\mathrm{N}$ protein in the lungs of COVID-19 patients via the lectin pathway ${ }^{19}$, it is

232 unclear how to develop a virus-free and an effective system for analyzing the role

233 of the SARS-CoV-2 N protein on complement hyperactivation. To this end, we

234 developed a clinical autoimmune disease serum-based protease enzymatic 235 approach to assess complement activation levels in the presence of the SARS-

236 CoV-2 N protein. Since complement activation initiated by the lectin pathway

237 features MASP-2 proteases by specific activity for cleaving complement 238 components 2 and 4 ( $\mathrm{C} 2$ and $\mathrm{C} 4)^{32}$, we designed a $\mathrm{C} 2$ internal quenched

239 fluorescent peptide-based analysis route for ex vivo complement hyperactivation

240 (Figure 4a). Briefly, serum was collected from the peripheral blood of volunteers

241 with an autoimmune disease, as their serum contains the necessary components

242 for complement activation characterized by elevated C3 levels (Extended Data

243 Table 6). Next, we collected the fluorescence signal from cleaved C2 synthetic

244 peptide substrates (2Abz-SLGRKIQI-Lys(Dnp)-NH $\mathrm{NH}_{2}$ in reaction mixtures

245 containing autoimmune disease serum in the absence or presence of the SARS-

246 CoV-2 N protein with or without the mAb nCoV396. The initial reaction rate $\left(v_{0}\right)$

247 was estimated at a single concentration of individual sera from duplicate

248 measurements over a range of substrate concentrations. The steady-state

249 reaction constants maximal velocity $\left(V_{\max }\right)$ and Michaelis constant $\left(\mathrm{K}_{\mathrm{m}}\right)$ were

250 determined for comparisons (Figure 4a). 
251 As shown in Figure $\mathbf{4 b}$, the calculated $V_{\max }$ of reactions without any other 252 exogenous proteins is 1.49 response units $(R U) \cdot \mathrm{s}^{-1}$. Additions of the SARS-CoV$2532 \mathrm{~N}$ protein (concentrations ranging from $0.5 \mu \mathrm{M}$ to $10 \mu \mathrm{M}$ ) in the reactions 254 remarkably elevate the $V_{\max }$ up to 2 -fold, ranging from $2.37 \sim 3.02 \mathrm{RU} \cdot \mathrm{s}^{-1}$. 255 Similarly, additions of the SARS-CoV-2 N protein led to an approximate 1.8-fold 256 increase in the $V_{\text {max }} / K_{m}$ values, which suggested that the specificity constant $257\left(\mathrm{~K}_{\mathrm{cat}} / \mathrm{K}_{\mathrm{m}}\right)$ of MASP-2 to substrates is increased in the presence of the viral $\mathrm{N}$ 258 protein as the enzyme concentrations are equivalent among the reactions 259 (Extended Data Table 7 - 8). To confirm the kinetic analyses, Hanes plots ([S]/V 260 versus [S]) were also drawn and found to be linear (Figure 4c). Therefore, the 261 addition of the SARS-CoV-2 $\mathrm{N}$ protein does not change the single substrate 262 binding site characterization of the enzymatic reactions. To assess the 263 suppression ability of $\mathrm{nCoV} 396$ to the SARS-CoV-2 $\mathrm{N}$ protein-induced 264 complement hyperactivation function, we next conducted complement 265 hyperactivation analyses at various $\mathrm{N}$ protein: $\mathrm{nCoV} 396$ ratios. As shown in 266 Figure $4 \mathrm{~d}$, the addition of the $\mathrm{N}$ protein elevates the $V_{\max }$ value up to 40 -fold (1:0 267 ratio), whereas the addition of the antibody $\mathrm{nCoV} 396$ decreases the $V_{\max }$ in a 268 dose-dependent manner (Extended Data Table 9). To further validate the 269 function of nCoV396, we next performed complement hyperactivation analyses in 270 five other serum samples from autoimmune disease donors. Consistently, the $271 V_{\max }$ of reactions was boosted in the presence of the $\mathrm{N}$ protein in all samples but 272 declined in the presence of both the mAb nCoV396 and the $\mathrm{N}$ protein (Figure 4e). 273 In conclusion, these results demonstrate that the SARS-CoV-2 N protein is 
274 capable of inducing complement hyperactivation ex vivo, not only by facilitating

275 the $V_{\max }$ of MASP-2 catalytic activity but also by enhancing the substrate binding

276 specificity in the reactions. The N-reactive mAb nCoV396 specifically

277 compromises the SARS-CoV-2 N protein-induced complement hyperactivation

278 within clinical serum samples.

\section{Discussion}

280 From a quickly recovered COVID-19 patient, we isolated 32 mAbs specifically 281 targeting the SARS-CoV-2 N protein. The binding affinity of mAbs ranged from 1

$282 \mathrm{nM}$ to $25 \mathrm{nM}$, which is comparable with the binding affinity of mature S protein283 reactive antibodies ${ }^{22,25-29}$ and the other mature antibodies identified during acute 284 infections ${ }^{33,34}$. The characteristics of the isolated $\mathrm{N}$-reactive mAbs are different 285 from those of the isolated S-reactive mAbs in COVID-19 patients during the early 286 recovery phase, suggesting that sampling time is pivotal for identifying differential 287 immune responses to different SARS-CoV-2 viral proteins.

288 The crystal structure of $\mathrm{nCoV} 396$ bound to SARS-CoV-2 N-NTD elucidates the 289 interaction mechanism of the complex between the first reported $\mathrm{N}$ protein290 reactive human $\mathrm{mAb}$ and its targeted $\mathrm{N}$ protein. Three conserved amino acids 291 (Q163, L167, and K169) in the N protein are responsible for nCoV396 recognition, 292 which provides evidence of cross-reactivity of nCoV396 to the $\mathrm{N}$ protein of 293 SARS-CoV or MERS-CoV. Intriguingly, the nCoV396 binding of SARS-CoV-2 N294 NTD undergoes several conformational changes, resulting in an enlargement of 295 the N-NTD RNA binding pocket enlargement and partial unfolding of the basic 
296 palm region. More importantly, this conformational change occurs in the CT tail of

297 the N-NTD, which may alter the positioning of individual domains in the context of

298 the full-length protein and lead to a potential allosteric effect for protein functions.

299 Complement is one of the first lines of defense in innate immunity and is 300 essential for cellular integrity and tissue homeostasis and for modifying the 301 adaptive immune response ${ }^{35}$. Emerging evidence suggests that the complement 302 system plays a vital role in a subset of critical COVID-19 patients, with features of 303 atypical acute respiratory distress syndrome, disseminated intravascular 304 coagulation, and multiple organ failure ${ }^{9,10,36}$. A few pieces of evidence show that 305 the $\mathrm{N}$ protein of highly pathogenic coronaviruses (SARS-CoV-2 and SARS-CoV) 306 is involved in the initiation of MASP-2-dependent complement activation ${ }^{19,21}$. 307 Encouragingly, critical COVID-19 patients treated with complement inhibitors, 308 including small molecules to the complement component C3 and an antibody 309 targeting the complement component C5, show remarkable therapeutic 310 outcomes $^{19}$. Currently, there are 11 clinical trials related to targeting the

311 complement pathway (https://clinicaltrials.gov). To avoid adverse effects of 312 human complement component-targeting therapy, a viral protein-specific 313 approach is warranted. The antibody nCoV396 isolated from COVID-19 314 convalescent patients is an excellent potential candidate with a high binding 315 affinity to the $\mathrm{N}$ protein and high potency to inhibit complement hyperactivation. 316 As revealed by atomic structural information, the binding may allosterically 317 change the full-length $\mathrm{N}$ protein conformation. To determine the role of $\mathrm{nCoV} 396$ 318 in the suppression of complement hyperactivation, we monitored MASP-2 
319 protease activity based on its specific fluorescence-quenched C2 substrate in

320 sera from autoimmune disease patients. The complete complement components

321 in the sera of patients with autoimmune disorders allow us to monitor the

322 activating effects of the SARS-CoV-2 $\mathrm{N}$ protein and its specific mAbs. Although

323 we cannot calculate the other steady-state enzymatic reaction constants as the

324 precise concentration of MASP-2 in serum is unknown, we identified the $V_{\max }$ of

325 the specific $\mathrm{C} 2$ substrate for the enzymatic reaction. We demonstrated that the

326 SARS-CoV-2 $\mathrm{N}$ protein elevated the $V_{\max }$ of the reaction, up to 40 -fold, in the

327 sera of all 7 individuals tested, while nCoV396 effectively suppressed the $V_{\max }$ of

328 the reaction mixtures. These results indicated that serum-based complement

329 activation analysis of autoimmune disease patients is a virus-free and an

330 effective method for examining complement activation mediated by the SARS-

331 CoV-2 N protein.

332 Although the precise interaction of the SARS-CoV-2 N protein with MASP-2

333 remains to be elucidated, our work defined the region on the SARS-CoV-2 N

334 protein recognized by the $\mathrm{mAb}$ nCoV396 that plays an important role in

335 complement hyperactivation and indicates that human mAbs from convalescents

336 could be a promising potential therapeutic candidate for the treatment of COVID-

33719.

\section{References}

3391 Epidemiology Working Group for Ncip Epidemic Response, Chinese

340 Center for Disease Control and Prevention. [The epidemiological 
characteristics of an outbreak of 2019 novel coronavirus diseases (COVID-19) in China]. Zhonghua Liu Xing Bing Xue Za Zhi 41, 145-151 (2020)

3442 Wiersinga, W. J., Rhodes, A., Cheng, A. C., Peacock, S. J. \& Prescott, H. 345 C. Pathophysiology, Transmission, Diagnosis, and Treatment of 346 Coronavirus Disease 2019 (COVID-19): A Review. Jama-J. Am. Med. $347 \quad$ Assoc. doi:10.1001/jama.2020.12839 (2020).

3483 Tang, N., Li, D. J., Wang, X. \& Sun, Z. Y. Abnormal coagulation 349 parameters are associated with poor prognosis in patients with novel $350 \quad$ coronavirus pneumonia. J Thromb. Haemost. 18, 844-847 (2020).

3514 Wang, D. W. et al. Clinical Characteristics of 138 Hospitalized Patients 352 With 2019 Novel Coronavirus-Infected Pneumonia in Wuhan, China. 353 Jama-J. Am. Med. Assoc. 323, 1061-1069 (2020).

3545 Zhu, N. et al. A Novel Coronavirus from Patients with Pneumonia in China, 355 2019. N. Engl. J. Med. 382, 727-733 (2020).

3566 Zhou, F. et al. Clinical course and risk factors for mortality of adult 357 inpatients with COVID-19 in Wuhan, China: a retrospective cohort study. $358 \quad$ Lancet 395, 1054-1062 (2020).

3597 Gattinoni, L. et al. COVID-19 Does Not Lead to a "Typical" Acute 360 Respiratory Distress Syndrome. Am. J. Respir. Crit. Care Med 201, 1299361 1300, (2020). 
3628 Magro, C. et al. Complement associated microvascular injury and 363 thrombosis in the pathogenesis of severe COVID-19 infection: A report of 364 five cases. Transl. Res. 220, 1-13 (2020).

3659 Cugno, M. et al. Complement activation in patients with COVID-19: A 366 novel therapeutic target. J. Allergy Clin Immunol 146, 215-217, (2020).

36710 Noris, M., Benigni, A. \& Remuzzi, G. The case of complement activation in 368 COVID-19 multiorgan impact. Kidney Int. 98, 314-322 (2020).

36911 Pang, R. T. et al. Serum proteomic fingerprints of adult patients with 370 severe acute respiratory syndrome. Clin. Chem. 52, 421-429, (2006).

37112 Chen, J. H. et al. Plasma proteome of severe acute respiratory syndrome 372 analyzed by two-dimensional gel electrophoresis and mass spectrometry. 373 Proc. Natl. Acad. Sci. U. S. A. 101, 17039-17044 (2004).

37413 Ramlall, V. et al. Immune complement and coagulation dysfunction in 375 adverse outcomes of SARS-CoV-2 infection. Nat. Med. (2020).

37614 Kang, S. et al. Crystal structure of SARS-CoV-2 nucleocapsid protein RNA 377

15 Ye, Q., West, A. M. V., Silletti, S. \& Corbett, K. D. Architecture and self380 binding domain reveals potential unique drug targeting sites. Acta Pharm. Sin. B, doi:10.1016/j.apsb.2020.04.009 (2020).

38216 Iserman, C. et al. Specific viral RNA drives the SARS CoV-2 nucleocapsid 383 to phase separate. bioRxiv, doi:10.1101/2020.06.11.147199 (2020). 
$38417 \mathrm{Li}$, J. Y. et al. The ORF6, ORF8 and nucleocapsid proteins of SARS-CoV2 inhibit type I interferon signaling pathway. Virus Res. 286, 198074, (2020).

38718 Perdikari, T. M. et al. SARS-CoV-2 nucleocapsid protein undergoes liquid388 liquid phase separation stimulated by RNA and partitions into phases of 389 human ribonucleoproteins. bioRxiv, doi:10.1101/2020.06.09.141101 $390 \quad$ (2020).

39119 Gao, T. et al. Highly pathogenic coronavirus N protein aggravates lung 392 injury by MASP-2-mediated complement over-activation. medRxiv, 2020.2003.2029.20041962, doi:10.1101/2020.03.29.20041962 (2020).

39420 Guo, Y. R. et al. The origin, transmission and clinical therapies on 395 coronavirus disease 2019 (COVID-19) outbreak - an update on the status.

22 Chi, X. et al. A neutralizing human antibody binds to the $\mathrm{N}$-terminal 401

21 Liu, J. L., Cao, C. \& Ma, Q. J. Study on interaction between SARS-CoV N Military Med. Res. 7, 11 (2020).

and MAP19. Xi bao yu fen zi mian yi xue za zhi = Chinese journal of cellular and molecular immunology 25, 777-779 (2009).

40424 Kreer, C. et al. Longitudinal Isolation of Potent Near-Germline SARS-CoV405 406 domain of the Spike protein of SARS-CoV-2. Science 369, 650-655 (2020).

23 Klasse, P. J. \& Moore, J. P. Antibodies to SARS-CoV-2 and their potential for therapeutic passive immunization. Elife 9, e57877 (2020).

2-Neutralizing Antibodies from COVID-19 Patients. Cell S0092-8674(20), 30821-30827 (2020). 
40725 Zost, S. J. et al. Potently neutralizing and protective human antibodies against SARS-CoV-2. Nature, doi:10.1038/s41586-020-2548-6 (2020).

$26 \mathrm{Wu}, \mathrm{Y}$. et al. A noncompeting pair of human neutralizing antibodies block COVID-19 virus binding to its receptor ACE2. Science 368, 1274-1278, (2020).

41227 Wang, C. et al. A human monoclonal antibody blocking SARS-CoV-2 infection. Nat. Commun. 11, 2251 (2020).

$41428 \mathrm{Ju}$, B. et al. Human neutralizing antibodies elicited by SARS-CoV-2 infection. Nature 584,115-119 (2020).

41629 Cao, Y. et al. Potent Neutralizing Antibodies against SARS-CoV-2 Identified by High-Throughput Single-Cell Sequencing of Convalescent Patients' B Cells. Cell 182, 73-84 (2020).

41930 Liao, H. X. et al. High-throughput isolation of immunoglobulin genes from 420 single human B cells and expression as monoclonal antibodies. J. Virol. Methods 158, 171-179 (2009).

31 Moody, M. A. et al. H3N2 influenza infection elicits more cross-reactive and less clonally expanded anti-hemagglutinin antibodies than influenza vaccination. PLoS One 6 (10): e25797 (2011).

32 Duncan, R. C. et al. Multiple domains of MASP-2, an initiating complement protease, are required for interaction with its substrate C4. Mol. Immunol. 49, 593-600 (2012).

33 Stettler, K. et al. Specificity, cross-reactivity, and function of antibodies elicited by Zika virus infection. Science 353, 823-826 (2016). 
$43034 \quad \mathrm{Yu}$, L. et al. Delineating antibody recognition against Zika virus during $431 \quad$ natural infection. JCl Insight 2 (12):e93042 (2017).

43235 Zipfel, P. F. \& Skerka, C. Complement regulators and inhibitory proteins. $433 \quad$ Nat. Rev. Immunol. 9, 729-740 (2009).

43436 Lo, M. W., Kemper, C. \& Woodruff, T. M. COVID-19: Complement, 435 Coagulation, and Collateral Damage. J. Immunol, doi: $436 \quad$ 10.4049/jimmunol.2000644 (2020). 


\section{Methods}

\section{Recombinant SARS-CoV-2 S-ECD and N proteins.}

Recombinant SARS-CoV-2 S protein (extracellular domain of the S protein (ECD) with His and FLAG Tags, Z03481) was purchased from GenScript. SARS-CoV-2 (formerly known as 2019-nCoV, recombinant full-length $\mathrm{N}$ protein with a CT $6 \mathrm{x}$ His tag (His tag, 40588-V08B) was purchased from Sino Biological. The SARSCoV-2 $\mathrm{N}$ protein expression plasmid (SARS-CoV N-FL) was a gift from the Guangdong Medical Laboratory Animal Center. SARS-CoV and MERS-CoV NFL were purchased from RuiBiotech. SARS-CoV-2 N-FL (residues 1 to 419), SARS-CoV-2 N-NTD domain (residues 41 to 174), SARS-CoV-2 N-CTD domain (residues 250 to 364), SARS-CoV N-FL and MERS-CoV N-FL were cloned into the pET-28a vector and expressed in the Rosetta E. coli strain. Expression of SARS-CoV-2 N-FL and variants in E. coli was induced with $0.1 \mathrm{mM}$ isopropylthio$\beta$-galactoside (IPTG) and cultured overnight at $16{ }^{\circ} \mathrm{C}$ in Terrific Broth media. Expressed recombinant $\mathrm{N}$ proteins were initially purified by using nickel column chromatography and further purified via size-exclusion chromatography.

\section{PBMCs from COVID-19 patients and sorting of single plasma cells and}

\section{memory B cells by FACS}

Blood samples were collected 9 - 25 days after the onset of the disease from patients who had recovered from COVID-19 infection. PBMCs and plasma were isolated from blood samples by Ficoll-Paque PLUS (GE, 17-1440-02) density gradient centrifugation. All work related to human subjects was carried out in 
460 compliance with Institutional Review Board protocols approved by the 461 Institutional Review Board of the Fifth Affiliated Hospital of Sun Yat-sen 462 University. Single plasma cells with the surface markers CD3-, CD14-, CD16-, $463 \mathrm{CD}^{2} 35 \mathrm{a}^{-}, \mathrm{CD} 19^{+}, \mathrm{CD} 20^{\text {low-neg }}, \mathrm{CD} 27^{\mathrm{hi}}$ and $\mathrm{CD} 38^{\text {hi }}$ and memory $\mathrm{B}$ cells with the

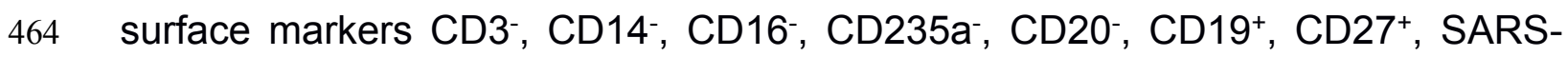
$465 \mathrm{CoV}-2 \mathrm{~S}^{+}$and SARS-CoV-2 $\mathrm{N}^{+}$(BD Biosciences and Invitrogen) were sorted into 466 individual wells in 96-well microtiter plates containing cell lysis and RT buffer for

467 Ig gene amplification by fluorescence activated cell sorting (FACS) as previously 468 described $^{37}$ on a BD FACS Aria SORP. Data were analyzed using BD FACS 469 Diva 8.0.1 software.

\section{Isolation and expression of $\lg \mathbf{V}_{\mathrm{H}}$ and $\mathrm{V}_{\mathrm{L}}$ genes}

471 Genes encoding $V_{H}$ and $V_{L}$ were amplified by reverse transcription (RT) and 472 nested primer chain reaction (PCR) and nested PCR using the method 473 previously described ${ }^{38}$. PCR products of $\lg V_{H}$ and $V_{L}$ genes were purified using 474 a PCR purification kit (QIAGEN), sequenced in forward and reverse directions 475 (Thermo Fisher scientific) and annotated by using IMGT/V-QUEST 476 (www.imgt.org/IMGT_vquest). Functional $V_{H}$ and $V_{L}$ genes were used for 477 assembling full-length Ig heavy and light chain linear expression cassettes by 478 one-step overlapping PCR ${ }^{38}$. HEK-293T cells in 12-well plates were transfected 479 with the assembled Ig heavy and light chain pairs derived from the same single 480 individual plasma cells using Effectene (QIAGEN) as the transfection reagent ${ }^{38}$.

481 Production of recombinant IgG and Fab antibodies 
482 For the production of purified full-length $\lg G 1$ antibodies, the $V_{H}$ and $V_{L}$ genes 483 were cloned into the pCDNA3.1 ${ }^{+}$(Invitrogen)mammalian expression vector 484 containing either the human IgG1 constant region gene, the human kappa light 485 chain constant region gene or the lambda light chain constant region gene using 486 standard recombinant DNA technology ${ }^{38}$. For the production of the purified 487 nCoV396Fab antibody, a stop codon TGA was introduced after the sequence (5'488 TCTTGTGACAAA-3'), which encodes the amino acid residues SCDK, just before 489 the hinge of the human $\lg G 1$ constant region ${ }^{39}$. Recombinant $\lg \mathrm{G} 1$ antibodies 490 and the nCoV396Fab antibody were produced in 293F cells cultured in serum491 free medium by cotransfection with the generated IgG1 full-length or Fab heavy492 and light chain gene expression plasmid pairs using polyethylenimine ${ }^{40}$. Full493 length IgG1 antibodies were purified by using Protein A column chromatography 494 as described previously ${ }^{38}$. The nCoV396Fab antibody used for the crystal 495 structure was purified by Lambda FabSelect, an affinity resin designed for the 496 purification of human Fab with a lambda light chain (GE Healthcare) ${ }^{39}$.

497 Analysis of the binding of plasma antibodies and isolated mAbs to the $\mathbf{S}$ 498 and $\mathbf{N}$ proteins by ELISA

499 We collected plasma from 6 patients and measured serum antibody titers using 500 recombinant SARS-CoV-2 $\mathrm{S}$ and $\mathrm{N}$ proteins as antigens to coat ELISA plates. 501 Antibodies in the supernatant of the transfected 293T cultures harvested 3 days 502 after transfection were screened by ELISA as described previously ${ }^{38}$. The binding 503 of purified antibodies to the $\mathrm{N}$ or $\mathrm{S}$ protein was also analyzed by ELISA. Briefly, 504 all protein antigens (S, N-FL, N-NTD (41-174), and N-CTD (250-364)) were used 
505 at $200 \mathrm{ng} /$ well to coat 96-well high-binding ELISA plates (Nunc 442404) using

506 carbonate-bicarbonate buffer at $\mathrm{pH}$ 9.6. Plates were incubated overnight at $4{ }^{\circ} \mathrm{C}$

507 and blocked at room temperature for $2 \mathrm{~h}$ with PBS blocking buffer containing $5 \%$

$508 \mathrm{w} / \mathrm{v}$ goat serum and $0.05 \%$ Tween-20. Plasma or supernatant of transfected

$509293 T$ cell cultures or purified mAbs in serial dilutions in PBS were incubated at

$51037{ }^{\circ} \mathrm{C}$ for $1 \mathrm{~h}$. Goat anti-human IgG-horseradish peroxidase (HRP, 1:10,000

511 dilution) (Promega, W4031) as the secondary antibody diluted in blocking buffer

512 was added and incubated at $37{ }^{\circ} \mathrm{C}$ for $1 \mathrm{~h}$. These plates were then washed 5

513 times with PBS and developed with $100 \mu \mathrm{L}$ of 3,3',5,5'-Tetramethylbenzidine

514 (TMB) substrate/well (Solarbio PR1200). The reaction of the plates was stopped

515 with $50 \mu \mathrm{L}$ of $2 \mathrm{M} \mathrm{H}_{2} \mathrm{SO}_{4} /$ well and read at a wavelength of $450 \mathrm{~nm}$ by an ELISA

516 reader. The relative affinity of $\mathrm{mAbs}$ to the $\mathrm{N}$ protein antigen was determined as

517 the effective concentration $\left(\mathrm{EC}_{50}\right)$ of the antibody resulting in half maximal

518 binding to the antigen by curve fitting with GraphPad Prism software.

519 Affinity and kinetic measurements by SPR

520 The binding affinity $\left(K_{D}\right)$, association rate $\left(k_{a}\right)$ and dissociation rate $\left(k_{d}\right)$ of purified

$521 \mathrm{mAbs}$ to the $\mathrm{N}$ protein were determined by SPR using a Biacore X100 System.

522 Anti-human Fc IgG antibody was first immobilized on a CM5-chip to

523 approximately $6,000 \mathrm{RU}$ by covalent amine coupling using a human antibody

524 capture kit (GE Healthcare). Purified mAbs were captured on channel 2 of the

$525 \mathrm{CM} 5$ chip to approximately $200 \mathrm{RU}$. Five 2 -fold serial dilutions of the $\mathrm{N}$ protein

526 starting at $40 \mu \mathrm{g} / \mathrm{ml}, 20 \mu \mathrm{g} / \mathrm{ml}, 10 \mu \mathrm{g} / \mathrm{ml}$ or $4 \mu \mathrm{g} / \mathrm{ml}$ were injected at a rate of 30

$527 \mu \mathrm{L} / \mathrm{min}$ for $90 \mathrm{~s}$ with a $600 \mathrm{~s}$ dissociation. The chip was regenerated by injection 
528 of $3 \mathrm{M} \mathrm{MgCl}_{2}$ for $30 \mathrm{~s}$. All experiments were performed at room temperature, and

529 data were analyzed using Biacore X100 Evaluation Software (version: 2.0.1).

530 Curves were fitted to a $1: 1$ binding model to determine the kinetic rate constants

$531 \quad\left(k_{a}\right.$ and $\left.k_{d}\right) . K_{D}$ values were calculated from these rate constants.

532 Crystallization and data collection

533 SARS-CoV-2 N-NTD (41-174) was cloned into the pRSF-Duet-1 vector with an

534 NT 6x His-SUMO tag, recombinantly expressed in E. coli and purified as an NT

535 6x His-Sumo-tagged protein. After Ni column chromatography followed by ulp1

536 digestion for tag removal, the SARS-CoV-2 N-NTD (41-174) protein was further

537 purified via size-exclusion chromatography. Prior to crystallization, the SARS-

538 CoV-2 N-NTD (41-174) sample was mixed with nCoV396Fab at a 1:1.5 molar

539 ratio for approximately half an hour and then further purified via size-exclusion

540 chromatography. Crystals were grown by the sitting drop method using a

541 Mosquito LCP crystallization robot with $0.3 \mu \mathrm{L}$ of protein $(6 \mathrm{mg} / \mathrm{ml})$ mixed with 0.3

$542 \mu \mathrm{L}$ of well solution at $16{ }^{\circ} \mathrm{C}$. Better crystals were obtained in $0.01 \mathrm{M}$ calcium

543 chloride dihydrate, $0.05 \mathrm{M}$ sodium cacodylate trihydrate $(\mathrm{pH} 7.2), 1.675 \mathrm{M}$

544 ammonium sulfate and $0.5 \mathrm{mM}$ spermine. The crystals were harvested after 3

545 days. Crystals were frozen in liquid nitrogen in the reservoir solution 546 supplemented with $25 \%$ glycerol $(\mathrm{v} / \mathrm{v})$ as a cryoprotectant. X-ray diffraction data

547 were collected at the Shanghai Synchrotron Radiation Facility BL18U at a 548 wavelength of $0.979 \AA$ and a temperature of $100 \mathrm{~K}$. The complex structure of 549 SARS-CoV-2 N-NTD with the mAb nCoV396 was determined by Phenix 550 molecular replacement using the SARS-CoV-2 N-NTD structure (PDB ID: 6M3M) 
551 and the monoclonal antibody omalizumab Fab (PDB ID: 6TCN) as the search

552 models. The X-ray diffraction and structure refinement statistics are summarized

553 in Extended Data Table 4. The final Ramachandran statistics are $97.1 \%$ favored,

$554 \quad 2.9 \%$ allowed and $0.0 \%$ outliers.

\section{Fluorescence-quenched substrate assays}

556 The fluorescence-quenched substrate (FQS) [C2 P4-P4' (2Abz-SLGRKIQI-

557 Lys(Dnp)-NH2)] was synthesized and purified in greater than $90 \%$ purity by 558 Sangon Biotech (Shanghai, China). The FQS was solubilized in $50 \%(\mathrm{v} / \mathrm{v})$ 559 dimethylformamide (DMF). Assays were carried out in fluorescence assay buffer 560 (FAB) (0.05 M Tris- $\mathrm{HCl}, 0.15 \mathrm{M} \mathrm{NaCl}, 0.2 \%$ (w/v) PEG 8,000, and $\mathrm{pH} 7.4)$ at $56137{ }^{\circ} \mathrm{C}$ using final substrate concentrations in the range of $2.8125-90 \mu \mathrm{M}$. A range 562 of substrate dilutions, performed in triplicate, were prepared in FAB and were 563 added to the wells at $100 \mu \mathrm{l} /$ well in the assay plates. The plates were incubated 564 at $37^{\circ} \mathrm{C}$ for 10 minutes. Five microliters of serum from autoimmune patients was 565 added to the mixture of the SARS-CoV-2 N protein with nCoV396 at a 1:1.2 566 molar ratio in the assay plates. Fluorescence intensity was measured on an 567 EnVision 2015 Multimode plate reader (PerkinElmer) at an excitation wavelength 568 of $320 \mathrm{~nm}$ and an emission wavelength of $420 \mathrm{~nm}$ for the FQS. The initial 569 reaction rate was estimated at a single concentration of enzyme from duplicate 570 measurements over a range of substrate concentrations. To determine steady571 state reaction constants $\left(V_{\max }\right.$, half saturation constant $\left(K_{0.5}\right)$ and Hill 572 coefficient( $(\mathrm{h})$ ), the experimental results were fitted using GraphPad Prism

573 Version 8.0 (GraphPad Software, San Diego, CA) to an equation describing 
574 positive cooperativity: $Y=V_{\max } \times \frac{x^{h}}{K 0.5^{h}+x^{h}}$, where 0.5 defines the relationship 575 between the reaction rate $(\mathrm{V})$ and the substrate concentration ([S]) when more 576 than one binding site applies.

\section{Methods references}

578 37. Morris, L. et al. Isolation of a human anti-HIV gp41 membrane proximal 579 region neutralizing antibody by antigen-specific single B cell sorting. PloS $580 \quad$ one 6, e23532 (2011).

581 38. Liao, H. X. et al. High-throughput isolation of immunoglobulin genes from 582 single human B cells and expression as monoclonal antibodies. J. Virol. 583 Methods 158, 171-179 (2009).

584 585 586

39. Nicely, N. I. et al. Crystal structure of a non-neutralizing antibody to the HIV-1 gp41 membrane-proximal external region. Nat. Struct. Mol. Biol. 17, 1492$1494(2010)$.

40. Smith, K. et al. Rapid generation of fully human monoclonal antibodies specific to a vaccinating antigen. Nat. Protoc. 4, 372-384 (2009). 


\section{Acknowledgement}

590 This work is supported by the COVID-19 Emerging Prevention Products,

591 Research Special Fund of Zhuhai City (ZH22036302200016PWC to S.C.;

592 ZH22036302200028PWC to F. X.; ZH22046301200011PWC to H-X. L.);

593 Emergency Fund from Key Realm R\&D Program of Guangdong Province 594 (2020B111113001) to H.S.; Zhuhai Innovative and Entrepreneurial Research 595 Team Program (ZH01110405160015PWC, ZH01110405180040PWC) to H-X. L; 596 We thank the staffs of the BL18U/19U/17U beamlines at SSRF for their help with 597 the X-ray diffraction data screening and collections. We thank Junlang Liang, 598 Tong Liu, Nan Li, Xiaoli Wang, Zhenxing Jia, and Jiaqi Li from Zhuhai Trinomab 599 Biotechnology Co., Ltd. for technical assistants of mAbs isolation, production and 600 characterization.

\section{Author Contributions}

602 S. C., H. S., F. X. and H-X. L. contributed the conception of the study and 603 established the construction of the article. S. C. and H-X. L. designed the 604 experiments and wrote the manuscript. S. K., M. Y., S. H. contributed to protein 605 purification and crystallization, in vitro protein-protein interaction analysis, and 606 complement activation analysis. Y. W. contributed to mAbs isolation, in vitro 607 protein-protein interaction analysis. S. C., S. K. M. Y., and S. H. performed 608 structural determination and validation. S. C., S. K., Y. W. drew figures. X. C., Y. 609 C., Q. C., Z. Z., Z. Z., Z. H., X. H., H. S., W. Z., and H. H. contributed to 
610 interpretation of data. Z. H., J. L., G. J., and F. X. contributed to clinical samples

611 collections. S.K., M.Y., S. H., Y.W. contributed equally to this work.

\section{Conflict of Interest}

613 The authors declare no conflict of interest.

\section{Data availability statement}

615 The structure in this paper is deposited to the Protein Data Bank with 7CR5 616 access code.

617 Additional Information

618 Correspondence and requests for materials should be addressed to Shoudeng

619 Chen (chenshd5@mail.sysu.edu.cn) and/or Hua-Xin Liao (tliao805@jnu.edu.cn). 


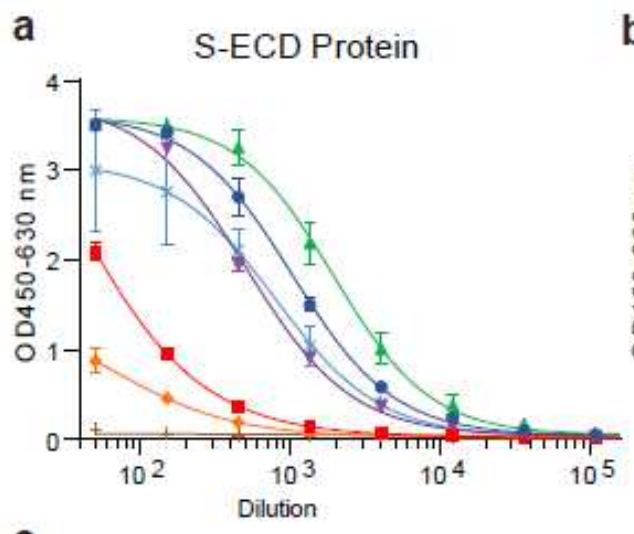

C
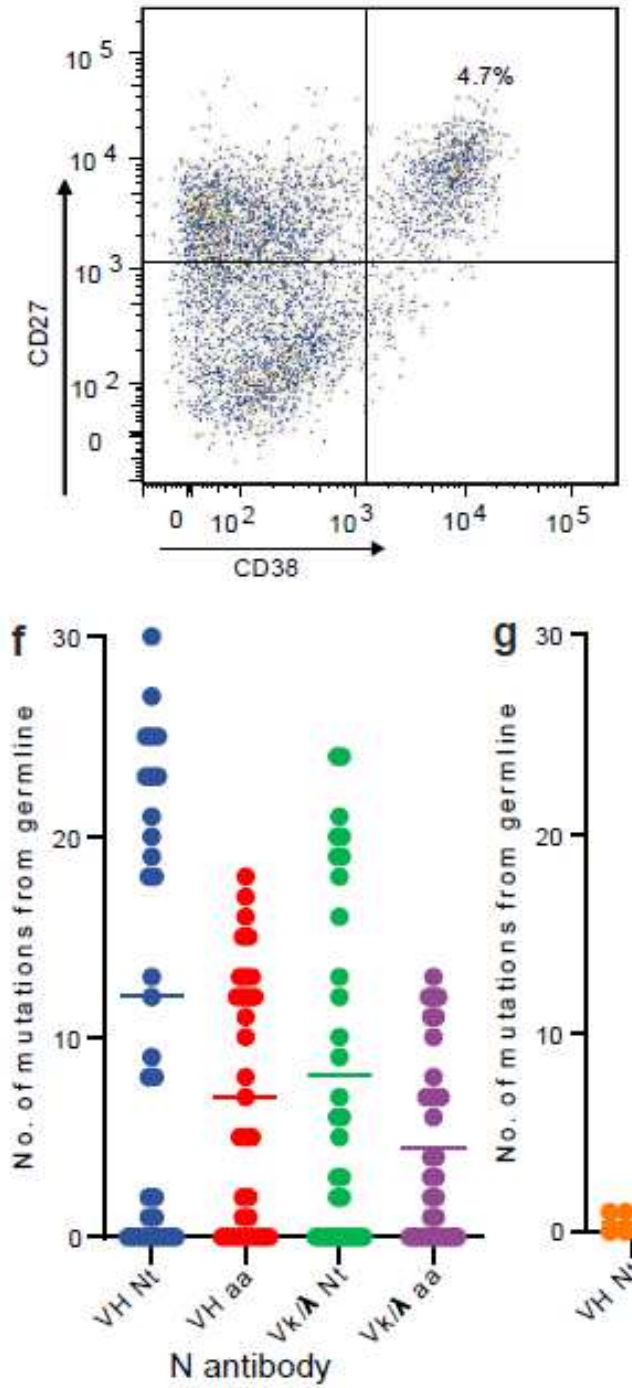

$(\mathrm{n}=32)$ b

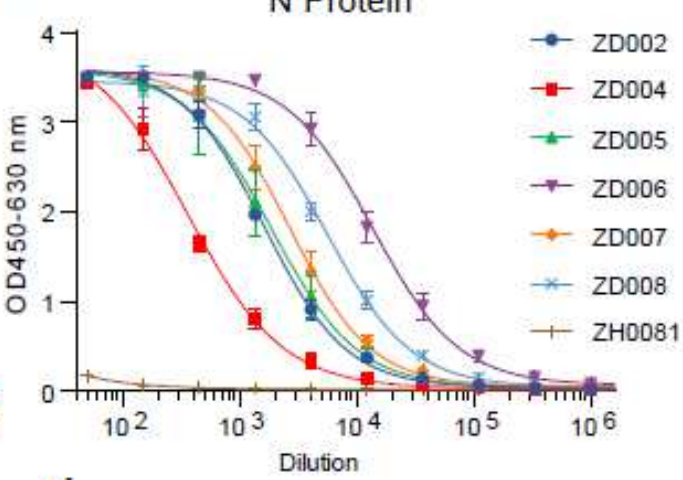

d
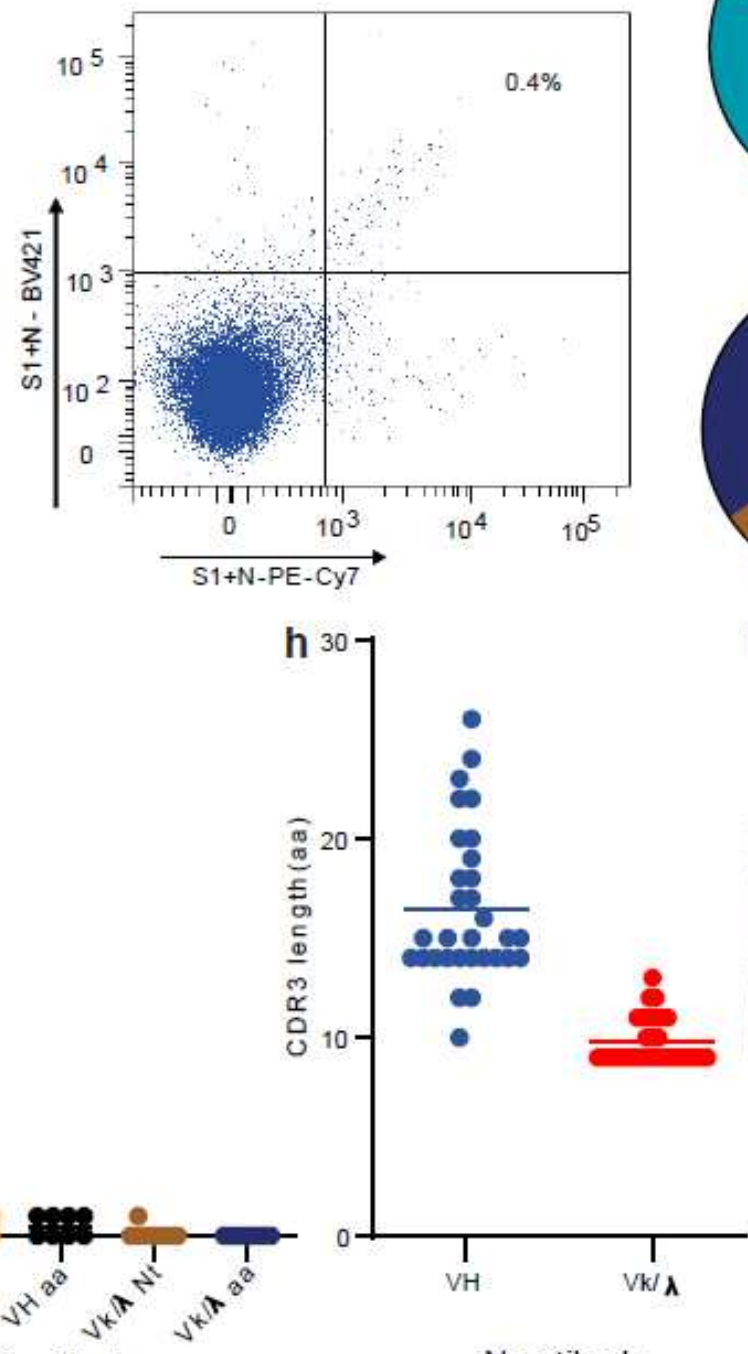

$\mathrm{N}$ antibody

( $\mathrm{n}=32$ )
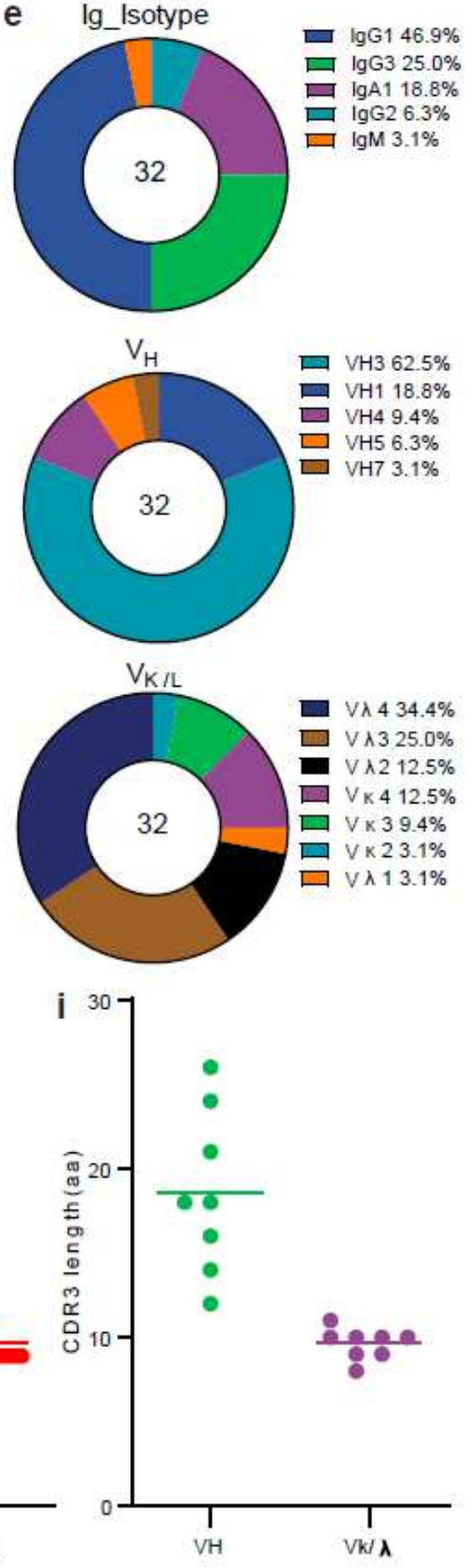

$S$ antibody $(\mathrm{n}=8)$

\section{Figure 1}

Acquisition and characterization of antibodies. Serum antibody titers of six SARS-CoV-2 convalescent patients to the SARS-CoV-2 S (a) and N (b) proteins measured by ELISA. Sorting of single plasma cells (c) with CD38 and CD27 double-positive B cells and single N and S proteinspecific memory B cells (d) by 
FACS. (e) Percentage of different isotypes, VH and VL gene families of 32 isolated N-reactive antibodies. (f) Number of mutations in nucleotides and amino acids in $\mathrm{VH}$ and $\mathrm{VL}(\mathrm{VK}$ and $\mathrm{V} \lambda$ ) of $32 \mathrm{~N}$-reactive antibodies and eight S-reactive antibodies (g). Length of the 32 Nreactive antibodies (h) and eight Sreactive antibodies (i) in $\mathrm{H}-\mathrm{CDR} 3$.
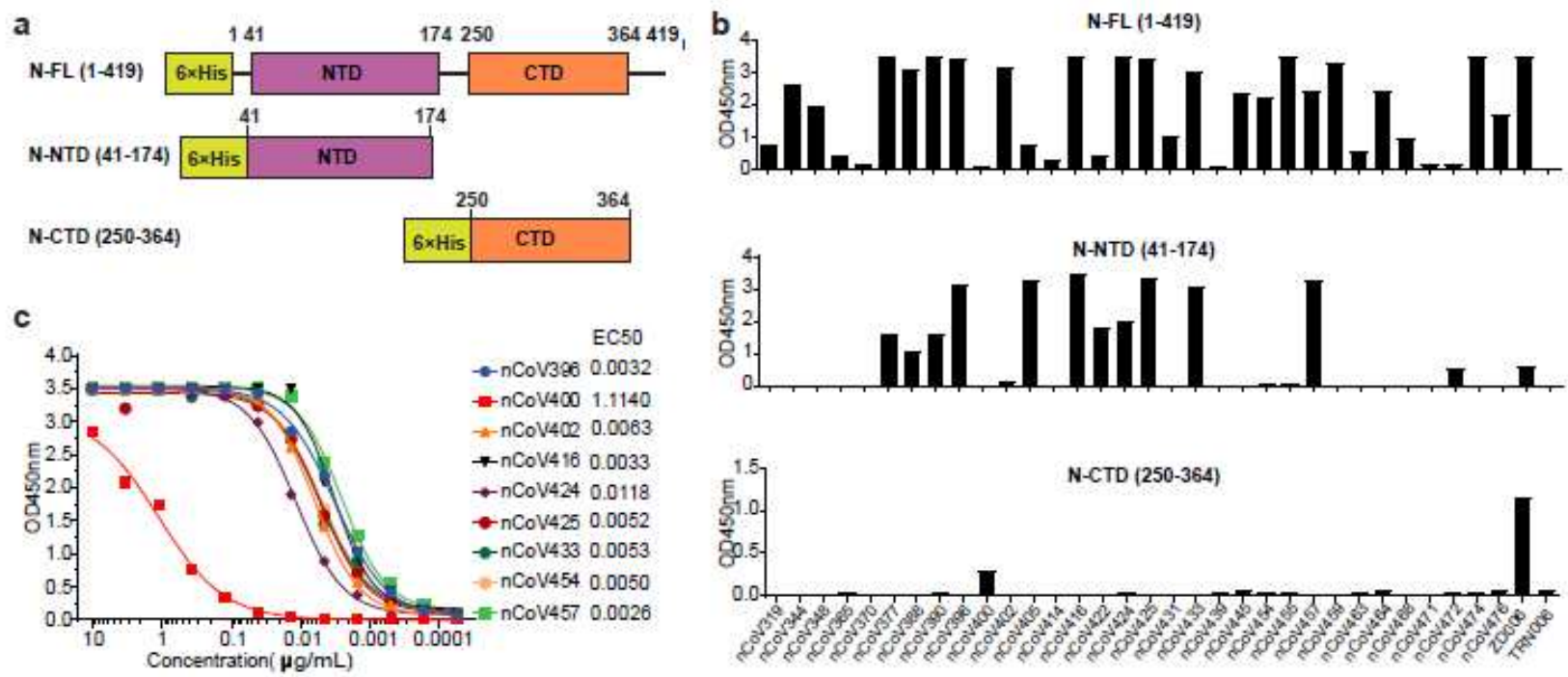

d
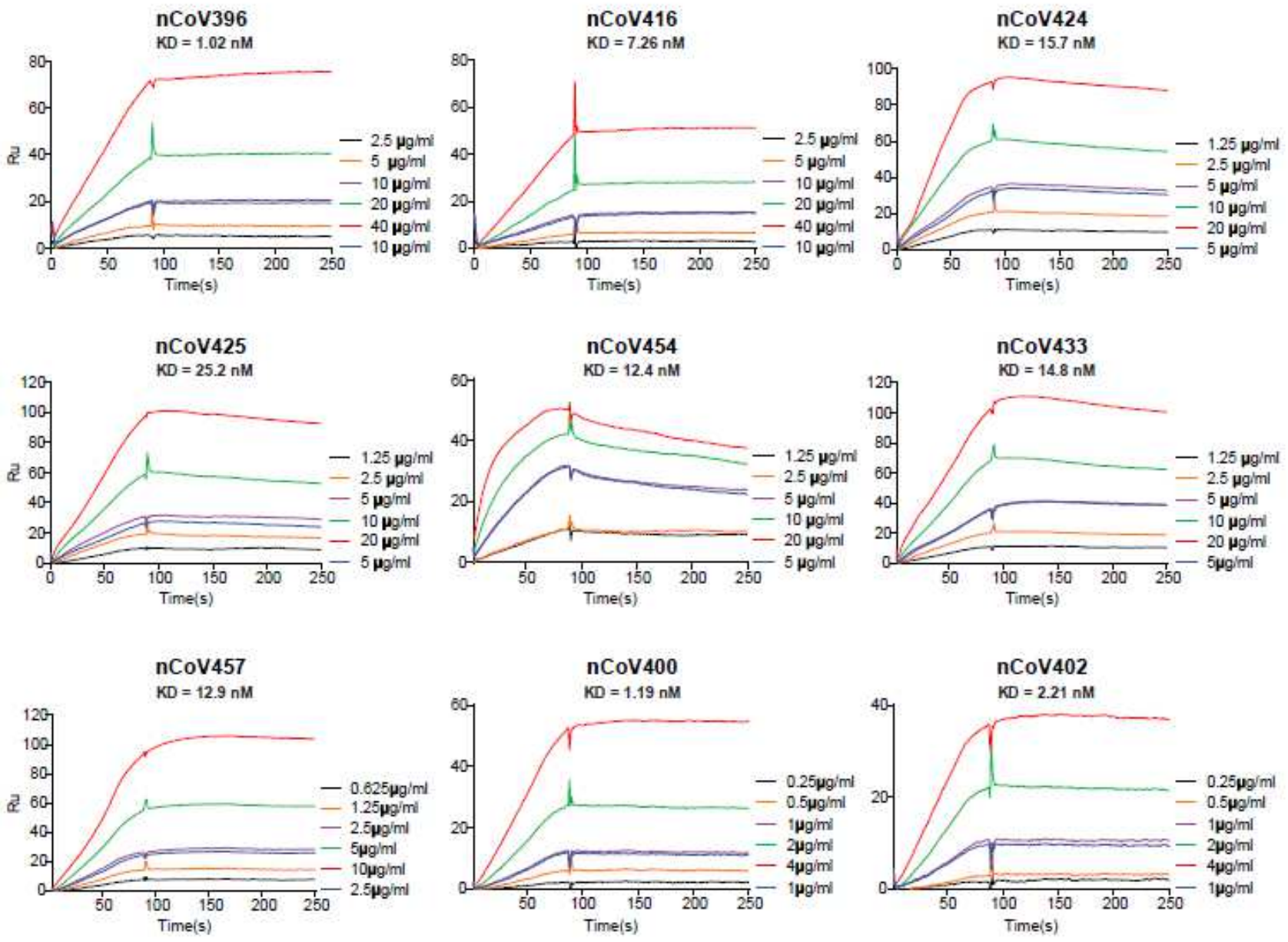

Figure 2 
Reactivity and affinity of the isolated antibodies to the $\mathrm{N}$ protein antigens. (a) Schematic presentation of the SARS-CoV-2 N protein and two variants. (b) Antibodies expressed in transfected 293 cells were evaluated for binding to N-FL, N-NTD and N-CTD by ELISA. Plasma from patient ZD006 and an irrelevant mAb TRN006 were used as the positive control and negative control, respectively. (c) The ability of nine purified antibodies to the N-FL protein was determined by ELISA. (d) Binding affinity of nine selected antibodies to the $\mathrm{N}$ protein was measured by SPR. KD values are shown above the individual plots.

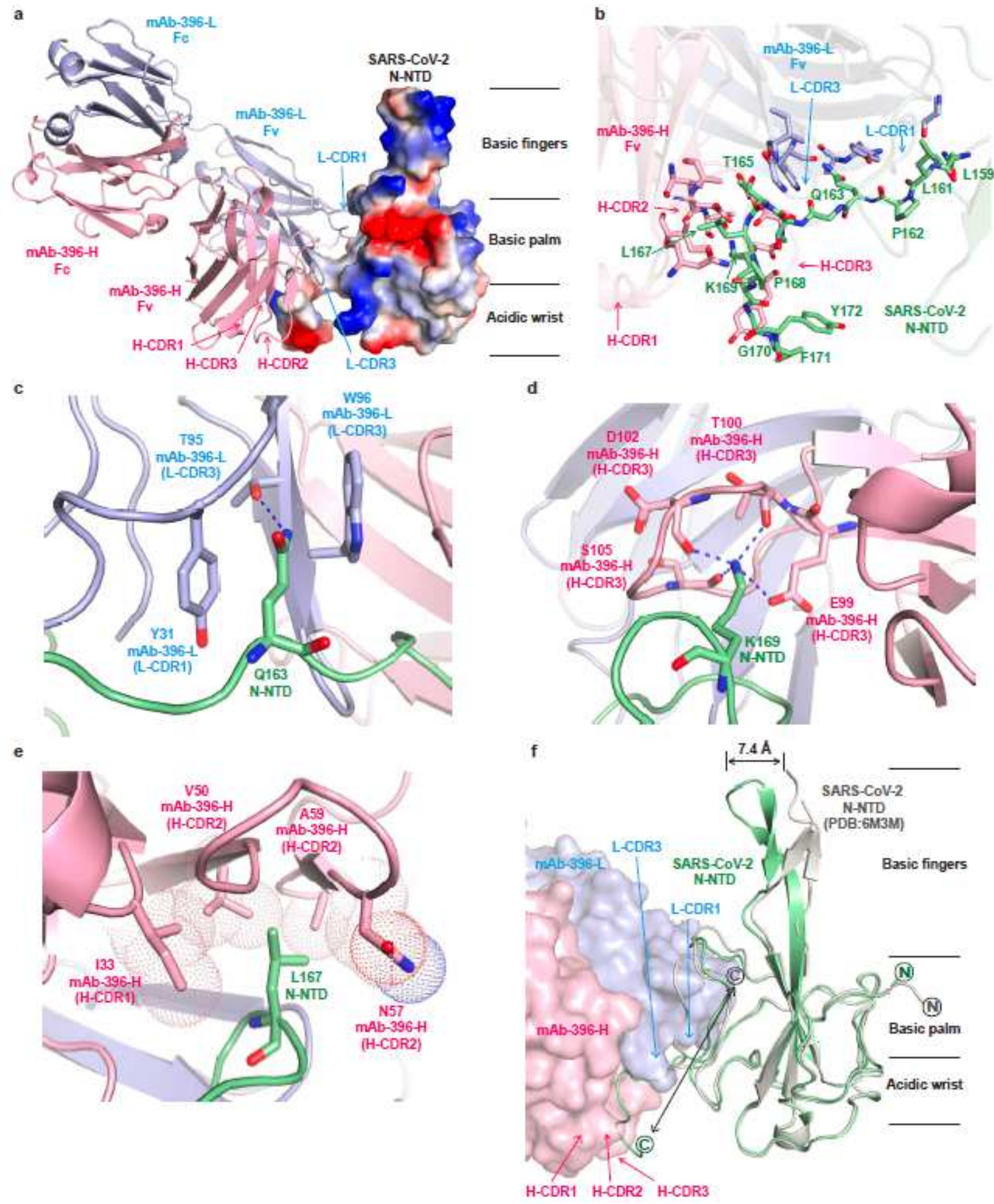


Complex structure of mAb nCoV396 with SARS-CoV-2 N-NTD(a) Overall structure of the mAb SARS-CoV-2 N-NTD complex. The light chain (pink) and heavy chain (blue) of mAb nCoV396 are illustrated with the ribbon representation. SARS-CoV-2 N-NTD is illustrated with an electrostatic surface, in which blue denotes a positive charge potential, while red indicates a negative charge potential. (b) The N-NGD epitope recognized by mAb nCoV396. The interacting residues of N-NTD and nCoV396 are highlighted with the stict representation. Recognition of Q163 (c),K169 (d) and L167 (e) in N-NTD by mAb nCoV396. The dashed blue line represents hydrogen bonds. Hydrophobic interactions are illustrated with the dot representation. (f) Conformational changes in N-NTD upon mAb nCoV396 binding. The apo structure of N-NTD is colored gray. Antibody-bound N-N口D is colored green. The N-terminus and C-terminus of the NNTD are labeled with circles. mAb nCoV396 is illustrated with surface representation. All figures were prepared by PyMol.

a

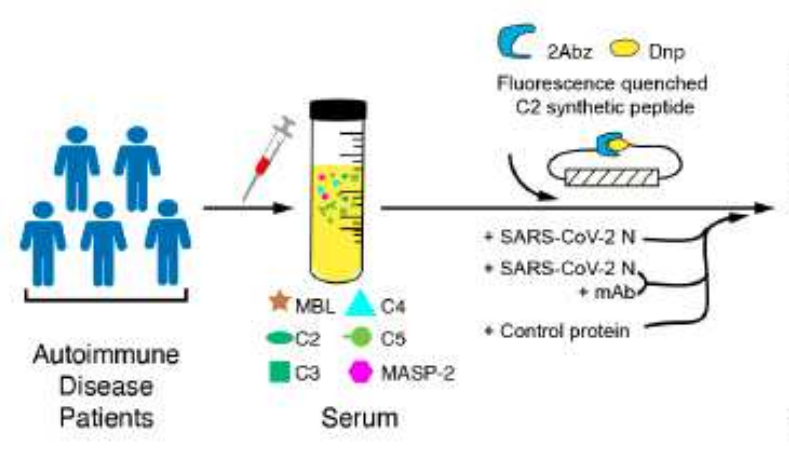

b

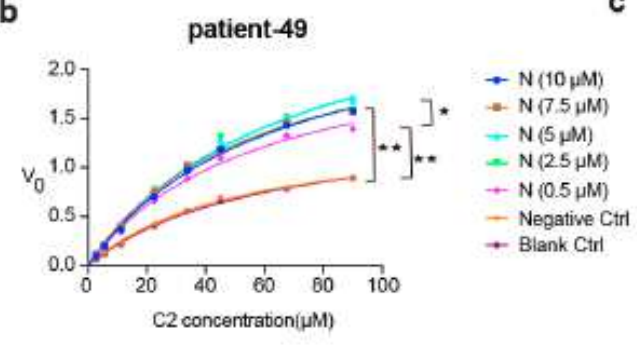

e
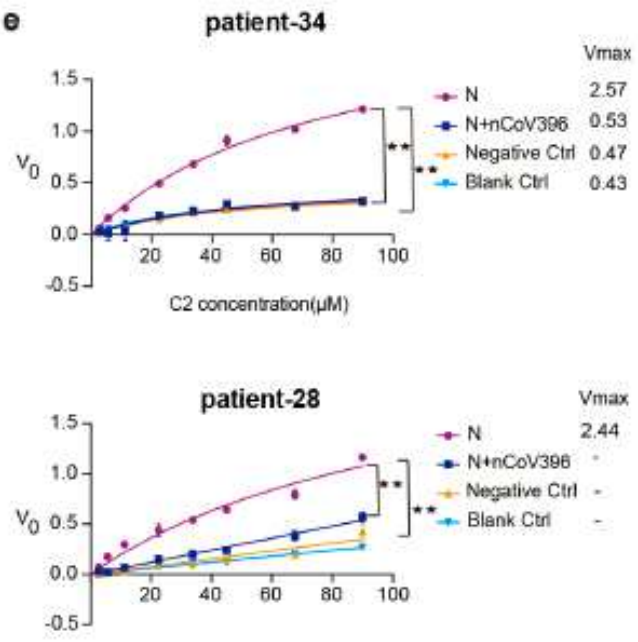

$\mathrm{C} 2$ concentration $(\mu \mathrm{M})$
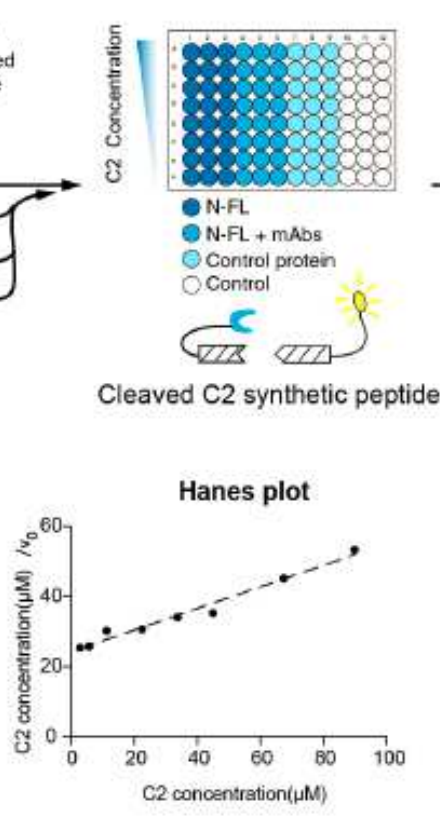

patient-19
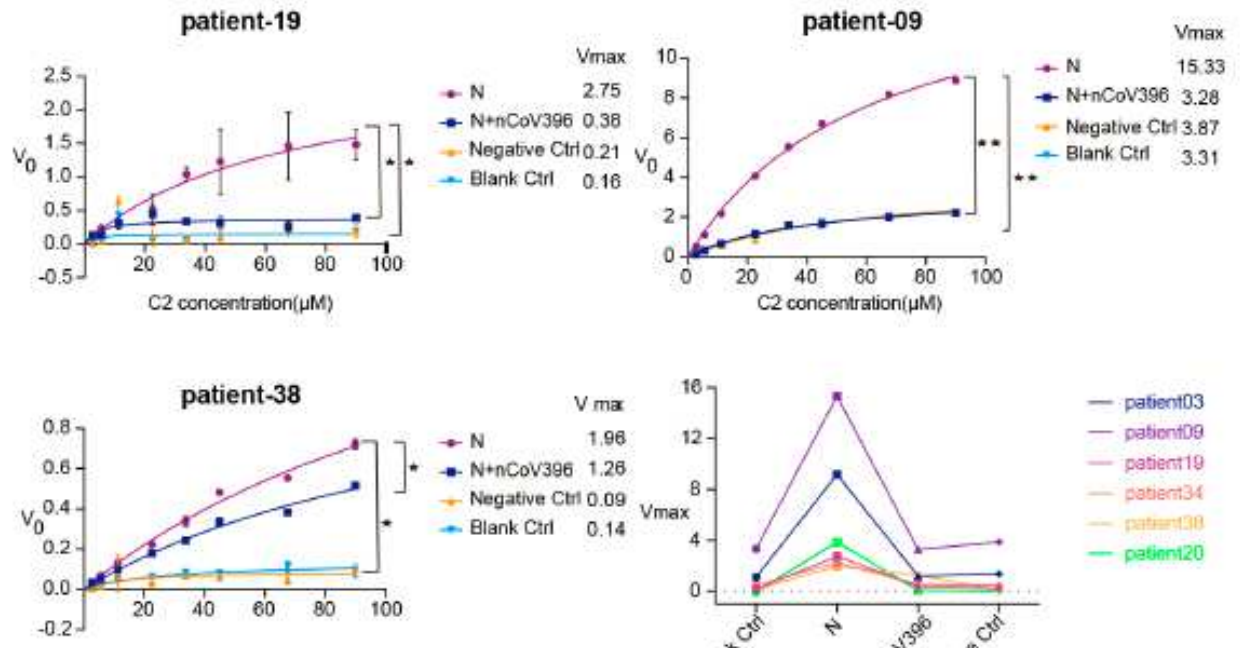

$\mathrm{C} 2$ concentration $(\mu \mathrm{M})$

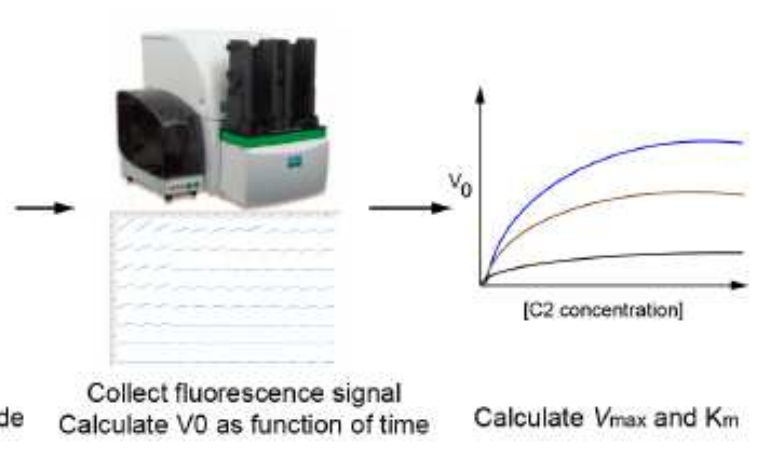

d

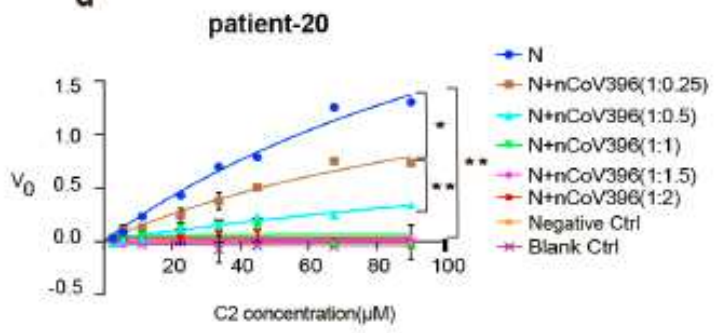

patient-09
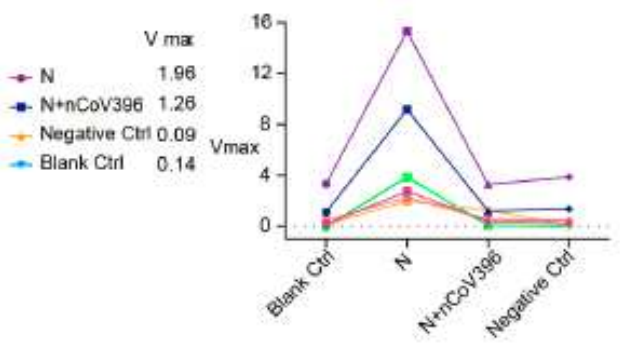

- patient03

- patient09

- patient19

- patient34

- patingra8

- patinnt20 
Antibody nCoV396 compromises SARS-CoV-2 N protein-induced complement hyperactivation. (a) Flow scheme of the SARS-CoV-2 N protein and nCoV396 influencing the protease activity of MASP-2 in the serum of autoimmune disease patients. The Michaelis-Menten curve shows the effect of increasing the $\mathrm{N}$ protein concentration (b) and antibody concentration (d) on the substrate C2 cleavage of MAPS-2 in the serum of patient 49 and patient 20. (c) A Hanes plot where $\mathrm{C} 2$ concentrationN0 is plotted against $\mathrm{C} 2$ concentration with the addition of $5 \mu \mathrm{M} \mathrm{N}$ protein. (e) The mAb nCoV396 inhibits the N protein-induced excessive cleavage of $\mathrm{C} 2$ in the serum of six autoimmune disease patients, and the last panel shows a summary of Vmax for all patients. Negative control (Negative Ctrl) and blank control (Blank Ctrl) represent reactions containing bovine serum albumin (BSA) instead of $\mathrm{N}$ or $\mathrm{N}+\mathrm{mAb}$ and without exogenous protein, respectively. The mean and standard deviation (SD) values of three technical replicates are shown. $P$ values: ${ }^{\star} P<0.05$; ${ }^{\star *} \mathrm{P}<0.01$; "-" indicates that the experimental kinetics did not conform to Michaelis-Menten kinetics.

\section{Supplementary Files}

This is a list of supplementary files associated with this preprint. Click to download.

- 5ExTFigTablesNC.pdf

- 4PDBNC.pdf 